\title{
Developing a Preliminary Causal Loop Diagram for Understanding the Wicked Complexity of the COVID-19 Pandemic
}

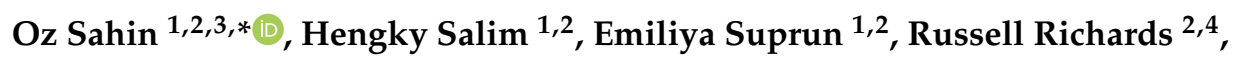 \\ Stefen MacAskill 1,2(D), Simone Heilgeist ${ }^{1,2} \mathbb{D}$, Shannon Rutherford ${ }^{5}$, Rodney A. Stewart ${ }^{1,2} \mathbb{D}$ \\ and Cara D. Beal 1,2,5 \\ 1 School of Engineering and Built Environment, Griffith University, Brisbane, QLD 4222, Australia; \\ hengky.salim@griffithuni.edu.au (H.S.); e.suprun@griffith.edu.au (E.S.); \\ stefen.macaskill@griffithuni.edu.au (S.M.); simone.heilgeist@griffithuni.edu.au (S.H.); \\ r.stewart@griffith.edu.au (R.A.S.); c.beal@griffith.edu.au (C.D.B.) \\ 2 Cities Research Institute, Griffith University, Brisbane, QLD 4222, Australia; r.richards@business.uq.edu.au \\ 3 Griffith Climate Change Response Program, Griffith University, Brisbane, QLD 4222, Australia \\ 4 UQ Business School, University of Queensland, Brisbane, QLD 4072, Australia \\ 5 School of Medicine, Gold Coast campus, Griffith University, Brisbane, QLD 4222, Australia; \\ s.rutherford@griffith.edu.au \\ * Correspondence: o.sahin@griffith.edu.au
}

Received: 9 May 2020; Accepted: 17 June 2020; Published: 18 June 2020

check for updates

\begin{abstract}
COVID-19 is a wicked problem for policy makers internationally as the complexity of the pandemic transcends health, environment, social and economic boundaries. Many countries are focusing on two key responses, namely virus containment and financial measures, but fail to recognise other aspects. The systems approach, however, enables policy makers to design the most effective strategies and reduce the unintended consequences. To achieve fundamental change, it is imperative to firstly identify the "right" interventions (leverage points) and implement additional measures to reduce negative consequences. To do so, a preliminary causal loop diagram of the COVID-19 pandemic was designed to explore its influence on socio-economic systems. In order to transcend the "wait and see" approach, and create an adaptive and resilient system, governments need to consider "deep" leverage points that can be realistically maintained over the long-term and cause a fundamental change, rather than focusing on "shallow" leverage points that are relatively easy to implement but do not result in significant systemic change.
\end{abstract}

Keywords: COVID-19; pandemic; wicked problem; systems approach; leverage points

\section{Introduction}

The COVID-19 pandemic has emerged as a problem of wicked complexity for policy makers internationally [1]. The virus and its necessary management strategies have thrown many countries into economic recession [2] and exacerbated existing social problems such as health care access, unemployment and inequality. A few countries have rapidly responded to the pandemic and have had success in its early containment, yet many countries have scrambled to implement interventions and measures when major implications of the disease started to appear.

Policy makers around the world have been mainly focusing on two key responses, namely, virus containment and financial measures for cushioning the resulting economic impact (i.e., jobs subsidies, unemployment benefits, government supported loans, etc.) [3]. However, they have been conducting these assessments separately from a "wait-and-see" perspective and often have not systematically 
examined this problem with consideration to a feasible and sustainable long-term strategy for managing the pandemic. Many countries have failed to learn from past epidemics of coronaviruses such as Severe Acute Respiratory Syndrome (SARS) and Middle East Respiratory Syndrome (MERS), where these types of viruses have historically long incubation periods [4]. A few countries have responded to this pandemic rapidly [5] with the readiness to sacrifice an early economic loss to prevent worse long-term economic impacts that would occur if the virus had spiralled out of control.

Systems thinking is a framework that can help policy makers to better understand the big picture through identifying the multi-faceted consequences of decision making in order to better weigh options and design the most effective strategies to manage the impacts of unintended consequences [6-8]. Effectively containing the virus and keeping the mortality rate low while maintaining economic, social and environmental goals is of importance in effectively managing this pandemic. The aim of this communication piece is to visualise the complexity in managing the COVID-19 pandemic through a systems lens by identifying the interconnectivity between health, economic, social and environmental aspects. This was explored via the development of a preliminary causal loop diagram (CLD) to identify important feedback loops. In the systems thinking field, CLD is a powerful tool for dealing with complex problems which has the ability to uncover the underlying feedback structures and leverage points in a system [9-11]. Moreover, causal loop modelling has been widely applied in health systems research [12-14].

\section{A Wicked Complexity}

In an increasingly connected world, the actions of individuals and governments and their resulting consequences are deeply entwined within the socio-economic and environmental systems. Recognising that the impacts of the COVID-19 pandemic transcend many boundaries (e.g., health, communities, science, politics, environment and economics) will help policy makers to determine the "right" intervention in a timely manner and implement additional interventions to reduce negative consequences. A CLD was developed to represent this complex problem through the identification of cause-and-effect links and feedback loops (Figure 1). This preliminary CLD was a product of the collective knowledge of the authors supported by geographical data by Johns Hopkins University [15] and a review of various governments' responses to the COVID-19 pandemic. The process of developing the preliminary CLD is presented in Appendix A.

Interventions (i.e., leverage points) are central to mitigating this pandemic. International travel restrictions, business restrictions, effectiveness of health crisis management, testing, awareness and social distancing campaigns and economic stimulus packages are among the interventions that have been implemented in many countries. Each intervention, undoubtedly, will have a trade-off between aspects of the system. An example is where the mandated "social distancing" rules can have a significant and immediate impact on business operations with potentially long-term economic and social consequences. Furthermore, delays will also exist in the system to indicate the time required for an intervention to be implemented or for a change to have an impact on the overall system. There is also a delay between the infection and when the symptoms appear (i.e., incubation period) which has caused more challenges in preventing an outbreak [16].

The existence of feedback loops within the system indicates two-way relationships between actions and consequences. These feedback loops can be used to identify if an intervention is able to create a system-wide change or if there is a need to improve or introduce a new solution. There are two types of feedback loops: reinforcing and balancing loops $[8,17]$. Reinforcing loops are responsible for the creation of an exponential growth or decay in the system, whereas balancing loops will balance a system until an equilibrium has been achieved. The dominance of reinforcing loops in this system indicates that there are more sources of growth, erosion and failure which decision makers need to address and minimise. Many countries have failed to realise and address these reinforcing loops [18]; thus, causing a near-collapse effect in the system that is exhibited by a massive outbreak in many countries. 


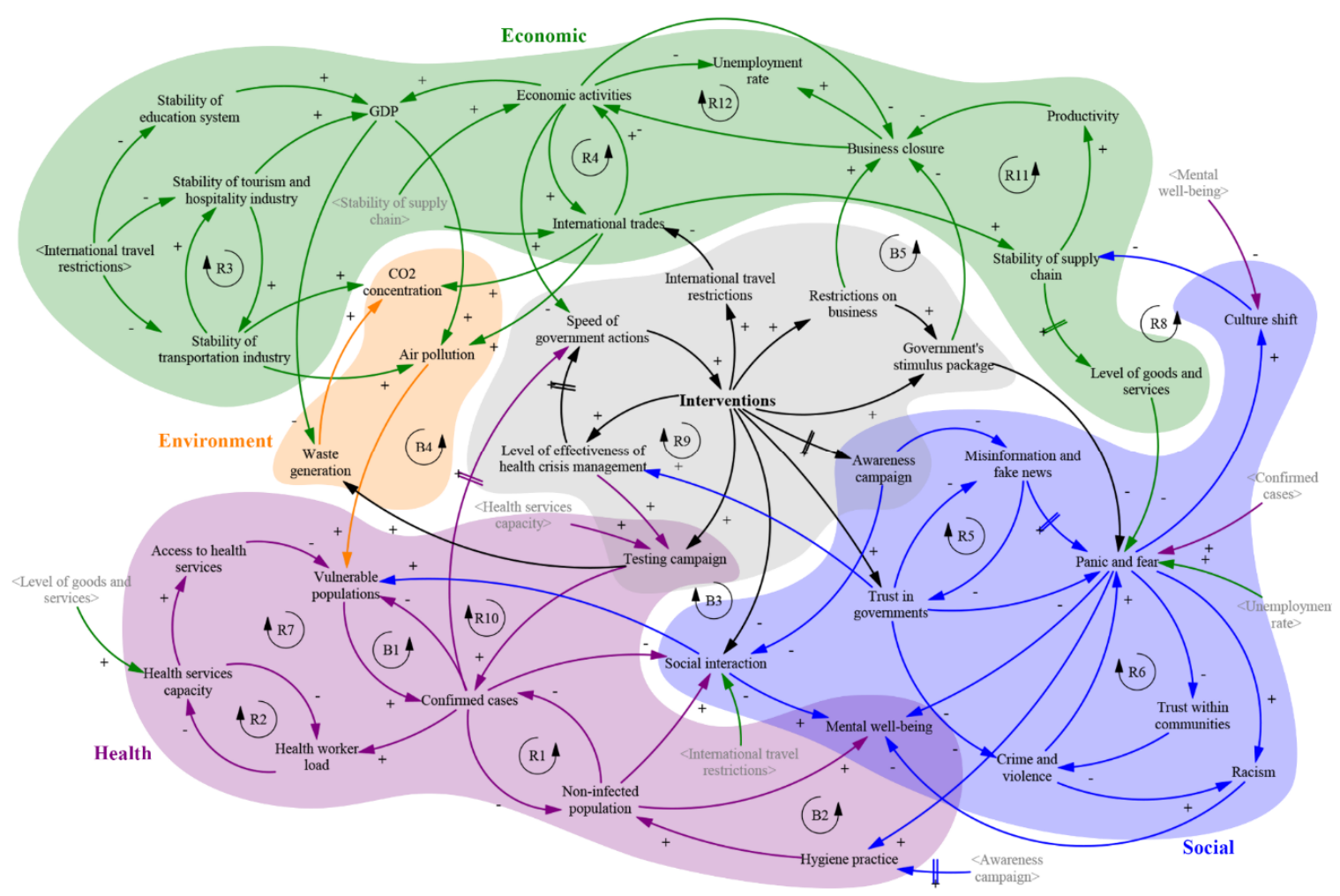

Figure 1. A preliminary causal loop diagram demonstrating the complexity of the COVID-19 pandemic environmental-health-socio-economic system.

We have seen in a very short time, how the gradual increase of interventions has led to unprecedented economic consequences [19]. The social distancing rules have created a restriction on some business operations; thus, some business closures are inevitable, consequently leading to an increase in unemployment rates (loop R12). The international and interstate travel restrictions have caused stock market volatility and have been prohibitive to international trading and mobility (loop R4 and R11). They also caused disruptions to almost every industry sector, including education systems and the interconnectivity between transport industries and the tourism and hospitality sector (loop R3). The International Monetary Fund (IMF) suggested that the world's economy will shrink by three percent this year, which is far worse than the 2008-2009 financial crisis [20]. This restrictive economic activity has led to some governments providing financial packages to affected businesses and employees (loop B5).

From the health perspective, a higher proportion of vulnerable populations will lead to a higher number of confirmed cases (loop B1). Population vulnerability is influenced by the accessibility of health services (loop R7); whilst a higher number of confirmed cases will increase health services' load (loop R2). However, fewer confirmed cases do not always reflect the actual infection rate as it is also dependent upon the effectiveness of the testing campaign (loop R10). Health care systems in many countries, particularly in developing countries, are overwhelmed with the exponential growth of cases [21-23]. Loop R9 (Figure 1) also demonstrates how a higher number of confirmed cases reinforces the speed of government actions that will lead to the introduction of additional measures. The non-infected loop can act as a reinforcing loop (R1) to reflect the number of recovered populations as well as a balancing loop (B6) if there is an increased risk of transmissions due to the increased extent of social interactions.

Conversely, positive environmental benefits should also be considered in the policy analysis system, such as the measurable decline in regional air pollution and greenhouse gas emissions due to reductions in ground and air travel. This improvement of air quality has been observed at a global scale as a result of decline in significant travel, business and social activities [24]. Although there has been a 
reduction on the waste generation volume due to a downward shift in economic activities, waste from personal protective equipment and testing kits will inevitably rise as the number of vulnerable in a population that need to be tested increases [25]. Furthermore, a culture shift related to panic buying will also contribute to food waste generation.

The human social network is the most challenging to manage in this pandemic with a high risk of catastrophic social order demise if inconsiderate policy is enacted [26]. This is a delicate balancing act; for example, maintaining social distancing will substantially reduce virus transmission (loop B3), however, long periods of isolation may have long lasting effects on mental well-being. Furthermore, this pandemic has caused global panic, heightened fear and eroded trust in governments and within communities. The prevalence of reinforcing loops R5 (trust), R6 (sense of security) and R8 (panic buying) reflects the increasing social issues that need to be addressed. We have seen multiple instances of societal behavioural changes such as panic buying (e.g., toilet paper and sanitiser), the emergence of organised crime, domestic violence, increased and targeted global xenophobia against certain ethnic groups $[18,27]$ and more recently abuse of health care workers as people's fears lead to irrationality and anxiety. These social problems stem from bounded rationality and responses to their panic and fear [28] where misinformation and confirmation bias may be contributing factors. Beside its social impacts, panic and fear may also increase hygiene practices among communities (loop B2).

\section{Placing Interventions in the Right Place at the Right Time}

Countries have taken different roads in addressing this global pandemic, leading to an activation of different leverage points. Two questions arise "Have the most widely used global interventions so far targeted relatively ineffective leverage points? Has current intervention been focused too heavily on 'shallow' leverage points?". As Meadows stated [8], there are twelve places in enacting leverage points ranging from "shallow" to "deep" (Figure 2). "Shallow" leverage points refer to interventions that are relatively easy to implement, yet bring a non-significant systemic change, while "deep" leverage points will cause a fundamental change.

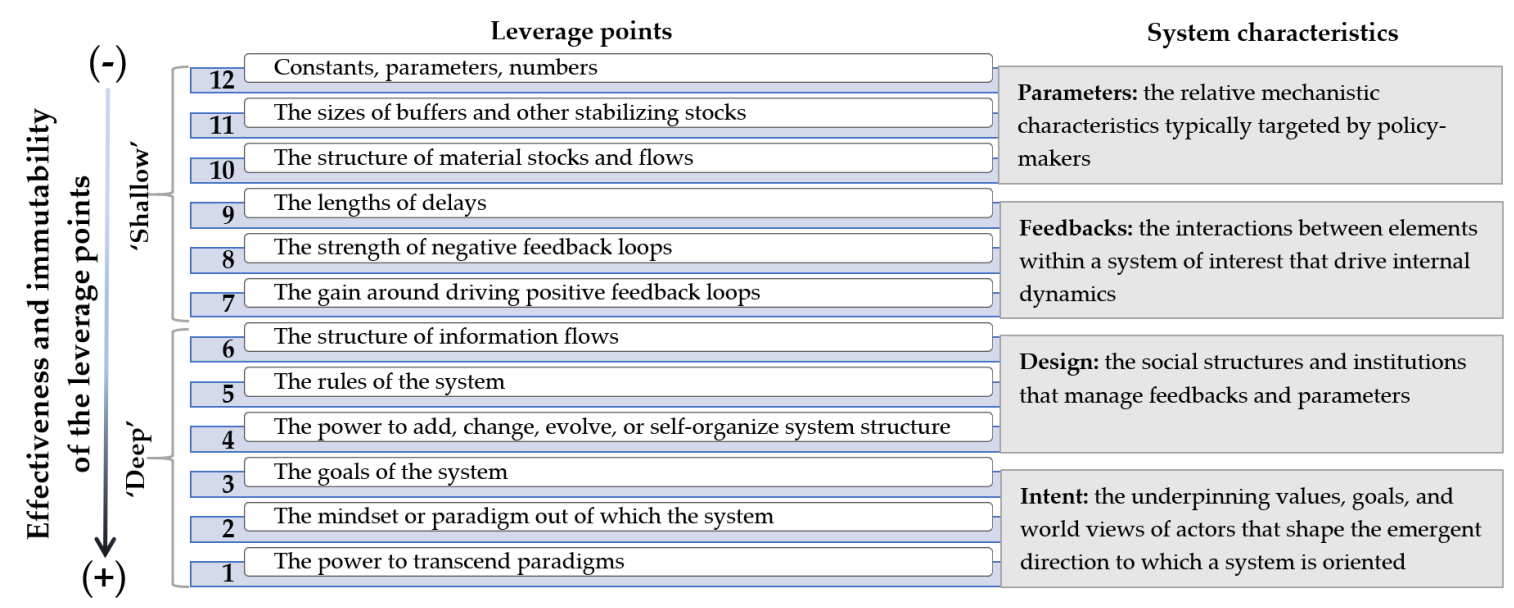

Figure 2. Leverage points to intervene a system. Adapted from Meadows [8].

Policies enacted in the interests of public health have had economic side effects. The extent, of course, will largely depend on the depth of the early intervention, the ability of governments to enact policy to limit the damage to the economy and the strength of the economy prior to the event. The travel restriction is a good example of both shallow and deep leveraging points as travel restrictions can change the direction to which a system is oriented by preventing infection being transmitted into a population by non-symptomatic carriers. Australia followed a series of largely ineffective (or shallow) international travel restrictions in the early stages where a ban was in place for flights from the source of the outbreak. It was not until it enacted a complete ban for all international and interstate flights (i.e., deeper leverage point) that the spread of new cases appeared to slow down. 
While encouraging social distancing and vigilance in personal hygiene are critical measures to reduce the risk of human-to-human transmission, it is challenging for the general public to consciously change their behaviour overnight and maintain these behaviours long-term [29]. Regardless of laws put in place, there remains a threat of public complacency, particularly once infection rates decrease. Government policies need to consider deeper leverage points that can be realistically maintained over the long-term, as infection rates trend up and down. Public confidence and trust in governance may be negatively impacted with regular "shallow", knee-jerk daily or weekly rule changes.

\section{Lessons Learned}

A systemic change could transcend the "wait and see" paradigm into a more proactive approach that is imperative for creating an adaptive and resilient system. Regardless of the approach taken, countries which have demonstrated a capacity to assess this problem systemically and comprehensively over various time horizons will emerge from this crisis in a much better position than those that have just tackled each incremental problem in an isolated and knee-jerk manner. It is possible that with a more proactive approach in implementing "deeper" interventions (deep leverage point), governments can be "flattening the curve" more effectively; consequently, limiting the impact of economic recession and associated socio-economic difficulties.

Government interventions will always struggle to completely prevent all types of virus transmission over the long term. However, effective government decisions must consider strategies that reduce infection rates, while dynamically accounting for the economic, social and environmental goals. Putting our "systems thinking" hat on to tackle this wicked problem, will help us to understand that there are always ever-moving and conflicting goals existing in any system, and will help those policy architects to develop best-practice (and deeper) interventions that will help to minimise unintended negative outcomes.

This communication piece reports on the development of a preliminary CLD which depicts the complexity and the multi-faceted nature of the COVID-19 pandemic from health, economic, social and environmental perspectives. This piece aims to demonstrate the COVID-19 pandemic complexity across health-socio-economic-environmental boundaries using a systems thinking visual as a precursor for the special issue "Life in the Time of a Pandemic: Social, Economic, Health and Environmental Impacts of COVID-19-Systems Approach Study" in the Systems journal. It is not intended to provide a full explanation of this issue but rather provide an example of how visualising the complexity of a system can help us to identify leverage points and the key important trade-offs that exist in the system. There remains a need to develop a system dynamics (SD) model that will be able to quantify this system. Such a model will assist policy makers in enacting an effective strategy for preparing nations in defending themselves against future pandemics by revealing the complexity, dynamic behaviour and trade-offs between different objectives. We would be foolish to not learn from the lessons around complexity and system interactions that this COVID pandemic has presented.

Author Contributions: O.S., H.S., E.S., R.R., S.M., and S.H. conducted stakeholder workshops, developed the preliminary causal loop diagram and drafted the manuscript. S.R., R.A.S., and C.D.B. conducted stakeholder workshops and improved the manuscript. All authors have read and agreed to the published version of the manuscript.

Funding: This research received no external funding.

Conflicts of Interest: The authors declare no conflict of interest. 


\section{Glossary}

Variable Name

Access to health services

Air pollution

Awareness campaign

Business closure

$\mathrm{CO}_{2}$ concentration

Confirmed cases

Crime and violence

Culture shift

Economic activities

GDP

Government's stimulus package

Health care worker load

Health services capacity

Hygiene practice

International trades

International travel restrictions

Interventions

Level of effectiveness of government

health crisis actions

Level of goods and services

Mental well-being

Misinformation and fake news

Non-infected population

Panic and fear

Productivity

Racism

Restrictions on business

Social interaction

Speed of government actions

Stability of education system

Stability of supply chain

Stability of tourism and hospitality industry

Stability of transportation industry

Testing campaign

Trust in governments

Trust within communities

Unemployment rate

Vulnerable populations

Waste generation

\section{Description}

Access into the health care system

The amount of harmful substances in earth's atmosphere

Marketing effort to educate individuals about an issue (e.g., need in regular hand washing, coverage of coughing/sneezing, usage of tissues and bin tissues, etc.)

Closure of businesses due both temporarily and due to bankruptcy

Concentration of carbon dioxide in earth's atmosphere

Positive tested population

Intentional harm

Shift in communities' culture (e.g., panic buying, business culture, etc.)

Stable manufacture of goods and the provision of services

Gross domestic product

Government's financial assistance to support businesses, households, and individuals

Number of patients per health care professional

Availability of facial masks, hospital beds, medication, treating medical staff, public health services

Regular hand washing, coverage of coughing/sneezing, usage of tissues and bin tissues

Export and import of goods and services

Travel ban to international flights to curb imported cases

Action plan of the government to controlling pandemic and its impacts

Effective operational action plan of the government; innovative steps to enable an effective intervention

Goods and services available in the market

Social and emotional well-being of individuals

Pseudo-news, deliberate disinformation, conspiracy theories or hoaxes spread via traditional news media or online social media

Fatalities, recovered, negative tested, non-tested population

Sudden anxiety, hysterical and irrational behaviour

Rate of goods and services being produced

Prejudice, discrimination, or hatred directed at someone because of their colour, ethnicity or national origin

Temporarily closure of non-essential businesses, 'take-away' only policy

Ability to meet (an)other individual(s)

Coordinated and timely operational action plan of the government to address health crisis

Uninterrupted work of education institutes, high number of enrolled

international students at universities

Uninterrupted distribution of goods and services, (i.e., no delays), availability of goods and services available in the market

Uninterrupted flow of both international and domestic visitors, stable work of hospitality businesses and events

Stable work of airlines, train services, shipping industries

Campaign to promote public awareness about COVID-19 testing if they have any symptom

Community trust and confidence towards parliament, the cabinet, the civil service, local councils, political parties, politicians

The degree of trust towards a certain group of people

Share of the labour force that is jobless

Elderly, socioeconomically disadvantaged (uninsured, homeless), individuals with a pre-existing medical condition

The amount of waste generated by households, industries and health systems 


\section{Appendix A}

Table A1. Development of the preliminary CLD through expert workshops.

\begin{tabular}{|c|c|c|c|c|c|}
\hline Modelling Workshops & Purpose & $\begin{array}{c}\text { Date and } \\
\text { Meeting Format }\end{array}$ & $\begin{array}{l}\text { Number of } \\
\text { Participants }\end{array}$ & $\begin{array}{l}\text { Participants' Area } \\
\text { of Expertise ** }\end{array}$ & $\begin{array}{l}\text { Confirmed COVID-19 } \\
\text { Cases, Australia }\end{array}$ \\
\hline $\begin{array}{l}\text { Workshop 1: } \\
\text { Problem scoping }\end{array}$ & $\begin{array}{l}\text { Identification of the key variables in regard } \\
\text { to impacts of the COVID-19 pandemic } \\
\text { Confirmation of the system boundary: } \\
\text { COVID-19 pandemic environmental-health- } \\
\text { socio-economic system }\end{array}$ & $\begin{array}{l}\text { March } 10 \text { 2020; } \\
\text { Face-to-face }\end{array}$ & 5 & $\begin{array}{l}\text { PH, S, CC, EM, ST, } \\
\text { MS, G, E, EngM }\end{array}$ & 116 \\
\hline $\begin{array}{l}\text { Workshop 2: Model } \\
\text { conceptualisation }\end{array}$ & $\begin{array}{l}\text { - Identification of relationships among } \\
\text { identified variables } \\
\text { - } \quad \text { Construction of a preliminary conceptual } \\
\text { model represented as a CLD }\end{array}$ & $\begin{array}{l}\text { March } 24 \text { 2020; } \\
\text { Face-to-face }\end{array}$ & 7 & $\begin{array}{c}\text { PH, S, CC, EM, ST, } \\
\text { MS, G, EngM, E, F, B }\end{array}$ & 2317 \\
\hline $\begin{array}{l}\text { Workshop 3: Model } \\
\text { confirmation }\end{array}$ & $\begin{array}{l}\text { - Refinement of the initial CLD generated } \\
\text { from the previous modelling workshop }\end{array}$ & $\begin{array}{l}\text { March } 29 \text { 2020; Video } \\
\text { conferencing * }\end{array}$ & 7 & $\begin{array}{l}\text { PH, S, CC, EM, ST, } \\
\text { MS, EngM, G, E, F, B }\end{array}$ & 4163 \\
\hline $\begin{array}{l}\text { Workshop 4: Model } \\
\text { confirmation (Cont.) }\end{array}$ & $\begin{array}{l}\text { - Identification of feedback loops } \\
\text { - Identification of interventions (i.e., } \\
\text { leverage points) }\end{array}$ & $\begin{array}{l}\text { April } 5 \text { 2020; Video } \\
\text { conferencing * }\end{array}$ & 4 & $\begin{array}{l}\text { S, CC, EM, ST, } \\
\text { MS, EngM, G, E }\end{array}$ & 5750 \\
\hline
\end{tabular}




\section{References}

1. Norman, C.D. Health promotion as a systems science and practice. J. Eval. Clean. Pract. 2009, 15, 868-872. [CrossRef] [PubMed]

2. Wearden, G.; Jolly, W. IMF: Global Economy Faces Worst Recession Since the Great Depression-As It Happened. The Guardian. 15 April 2020. Available online: https://www.theguardian.com/business/live/20 20/apr/14/stock-markets-china-trade-global-recession-imf-forecasts-covid-19-business-live (accessed on 20 April 2020).

3. Anderson, R.M.; Heesterbeek, H.; Klinkenberg, D.; Hollingsworth, T.D. How will country-based mitigation measures influence the course of the COVID-19 epidemic? Lancet 2020, 395, 931-934. [CrossRef]

4. Prompetchara, E.; Ketloy, C.; Palaga, T. Immune responses in COVID-19 and potential vaccines: Lessons learned from SARS and MERS epidemic. Asian Pac. J. Allergy 2020, 38, 1-9. [CrossRef]

5. Barron, L. What We Can Learn from Singapore, Taiwan and Hong Kong about Handling Coronavirus. Time. 13 March 2020. Available online: https://time.com/5802293/coronavirus-covid19-singapore-hong-kong-tai wan/ (accessed on 22 April 2020).

6. Da Luke, D.A.; Stamatakis, K.A. System science methods in public health: Dynamics, networks, and agents. Annu. Rev. Public Health 2012, 33, 357-376. [CrossRef] [PubMed]

7. Suprun, E.; Sahin, O.; Stewart, R.A.; Panuwatwanich, K. Model of the Russian Federation construction innovation system: An integrated participatory systems approach. Systems 2016, 4, 29. [CrossRef]

8. Meadows, D.H. Thinking in Systems; Chelsea Green Publishing: White River Junction, VT, USA, 2008.

9. Bureš, V. A method for simplification of complex group causal loop diagrams based on endogenisation, encapsulation and order-oriented reduction. Systems 2017, 5, 46. [CrossRef]

10. Agnew, S.; Smith, C.; Dargusch, P. Causal loop modelling of residential solar and battery adoption dynamics: A case study of Queensland, Australia. J. Clean. Prod. 2018, 172, 2363-2373. [CrossRef]

11. Garrity, E.J. Using systems thinking to understand and enlarge mental models: Helping the transition to a sustainable world. Systems 2018, 6, 15. [CrossRef]

12. Rees, D.; Cavana, R.Y.; Cumming, J. Using cognitive and causal modelling to develop a theoretical framework for implementing innovative practices in primary healthcare management in New Zealand. Health Syst. 2018, 7, 51-65. [CrossRef]

13. Lembani, M.; de Pinho, H.; Delobelle, P.; Zarowsky, C.; Mathole, T.; Ager, A. Understanding key drivers of performance in the provision of maternal health services in eastern cape, South Africa: A systems analysis using group model building. BMC Health Serv. Res. 2018, 18, 912. [CrossRef]

14. Littlejohns, L.B.; Baum, F.; Lawless, A.; Freeman, T. The value of a causal loop diagram in exploring the complex interplay of factors that influence health promotion in a multisectoral health system in Australia. Health Res. Policy Syst. 2018, 16, 126. [CrossRef] [PubMed]

15. Dong, E.; Du, H.; Gardner, L. An interactive web-based dashboard to track COVID-19 in real time. Lancet 2020, 20, 533-534. [CrossRef]

16. Lauer, S.A.; Grantz, K.H.; Bi, Q.; Jones, F.K.; Zheng, Q.; Meredith, H.R.; Azman, A.S.; Reich, N.G.; Lessler, J. The incubation period of coronavirus disease 2019 (COVID-19) from publicly reported confirmed cases: Estimation and application. Ann. Intern. Med. 2020, 172, 577-582. [CrossRef] [PubMed]

17. Sterman, J. Business Dynamics: Systems Thinking and Modeling for a Complex World; McGraw-Hill: New York, NY, USA, 2000.

18. Bradley, D.T.; Mansouri, M.A.; Kee, F.; Garcia, L.M.T. A systems approach to preventing and responding to COVID-19. EClinicalMedicine 2020. [CrossRef] [PubMed]

19. McKibbin, W.J.; Fernando, R. The global macroeconomic impacts of COVID-19: Seven scenarios. CAMA Work. Pap. 2020, 19. [CrossRef]

20. International Monetary Fund. World Economic Outlook Reports; International Monetary Fund: Washington, DC, USA, 2020.

21. Gilbert, M.; Pullano, G.; Pinotti, F.; Valdano, E.; Poletto, C.; Boëlle, P.; D'Ortenzio, E.; Yazdanpanah, Y.; Eholie, S.P.; Pharm, M.A.; et al. Preparedness and vulnerability of African countries against importations of COVID-19: A modelling study. Lancet 2020, 395, 871-877. [CrossRef]

22. Loayza, N.V.; Pennings, S. Macroeconomic Policy in the Time of COVID-19: A Primer for Developing Countries; World Bank: Washington, DC, USA, 2020. 
23. Grasselli, G.; Pesenti, A.; Cecconi, M. Critical care utilization for the COVID-19 outbreak in Lombardy, Italy: Early experience and forecast during an emergency response. JAMA 2020. [CrossRef]

24. Muhammad, S.; Long, X.; Salman, M. COVID-19 pandemic and environmental pollution: A blessing in disguise? Sci. Total Environ. 2020, 728, 138820. [CrossRef]

25. World Health Organization. Water, Sanitation, Hygiene and Waste Management for the COVID-19 Virus. Available online: https://apps.who.int/iris/bitstream/handle/10665/331305/WHO-2019-NcOV-IPC_WASH-2 020.1-eng.pdf (accessed on 7 May 2020).

26. Galea, S.; Merchant, R.M.; Lurie, N. The mental health consequences of COVID-19 and physical distancing: The need for prevention and early intervention. JAMA Intern. Med. 2020. [CrossRef]

27. Habibi, R.; Burci, G.L.; de Campos, T.C.; Chirwa, D.; Cinà, M.; Dagron, S.; Eccleston-Turner, M.; Forman, L.; Gostin, L.O.; Meier, B.M.; et al. Do not violate the International Health Regulations during the COVID-19 outbreak. Lancet 2020, 395, 664-666. [CrossRef]

28. Sterman, J.D.; Dogan, G. I'm not hoarding, I'm just stocking up before the hoarders get here: Behavioral causes of phantom ordering in supply chains. J. Oper. Manag. 2015, 39-40, 6-22. [CrossRef]

29. Van Bavel, J.J.; Baicker, K.; Boggio, P.S.; Capraro, V.; Cichocka, A.; Cikara, M.; Crockett, A.J.; Crum, A.J.; Douglas, K.M.; Druckman, J.N.; et al. Using social and behavioural science to support COVID-19 pandemic response. Nat. Hum. Behav. 2020, 4, 460-471. [CrossRef] [PubMed]

(C) 2020 by the authors. Licensee MDPI, Basel, Switzerland. This article is an open access article distributed under the terms and conditions of the Creative Commons Attribution (CC BY) license (http://creativecommons.org/licenses/by/4.0/). 